\title{
Intuitions in Philosophy: A Minimal Defense*
}

\author{
David J. Chalmers
}

In Philosophy Without Intuitions, Herman Cappelen focuses on the metaphilosophical thesis he calls Centrality: Contemporary analytic philosophers rely on intuitions as evidence for philosophical theories. Using linguistic and textual analysis, he argues that Centrality is false. He also suggests that because most philosophers accept Centrality, they have mistaken beliefs about their own methods.

To put my own views on the table: I do not have a large theoretical stake in the status of intuitions, but unreflectively I find it fairly obvious that many philosophers, including myself, appeal to intuitions. Cappelen's arguments make a provocative challenge to this unreflective background conception. So it is interesting to work through the arguments to see what they might and might not show. I think we can articulate a minimal (not heavily theoretical) notion of intuition that captures something of the core everyday philosophical usage of the term, and that captures the sense in which it seems obvious that philosophers rely on intuitions. I think the claim that philosophers rely on intuitions in this minimal sense remains strong enough to be interesting, and remains plausible in light of Cappelen's analysis.

Much depends on what counts as an intuition. Cappelen does not give a definition of 'intuition', but in his textual analysis, he uses three main diagnostics for intuitions: (F1) they have a special phenomenology, (F2) they have a special epistemic status, in that they justify but do not need justification, and (F3) they are based solely on conceptual competence. He goes on to argue that in a number of well-known philosophical texts that are often taken to appeal to intuitions, there is little evidence that authors are appealing to judgments with any of these three features.

It is not obvious that these three features capture the core notion of intuition at play in philosophical discussion. While the features may be attributed to intuitions by theorists such as Bealer (1992), Cappelen needs to show not just that Bealer is wrong, but that most philosophers' selfconception is wrong. To flesh out this worry: I think that using an everyday philosophical notion

*Forthcoming in a symposium in Philosophical Studies. 
of intuition, some intuitions in philosophy may satisfy Cappelen's criteria (F1)-(F3), but only a minority, and many of the most important intuitions do not. My view is that (F1) is really a theoretical claim about intuitions that may or may not be true, and (F3) holds at most for a subclass of intuitions. (F2) is by far the most important of the three features, but even this feature needs qualification.

Concerning (F1): this involves a certain theory of intuitions. It is highly controversial whether there is such a thing as a phenomenology of cognition, distinct from sensory phenomenology. Many theorists deny that there is such phenomenology, so deny that there is anything that could serve as the phenomenology of intuition (assuming, plausibly, that the phenomenology is not sensory). But these theorists are not ipso facto denying that there are intuitions. They simply hold that they lack a special phenomenology.

Concerning (F3): there are many paradigmatic intuitions that are not (or are at least not obviously) deliverances of conceptual competence. These include moral intuitions and other normative intuitions: the view that these stem from conceptual competence alone is widely rejected (as is the associated view that core moral claims are analytically true). They also include linguistic intuitions, which are widely held to stem from linguistic competence that goes well beyond conceptual competence. They include phenomenological intuitions, which plausibly stem from introspection rather than conceptual competence. There are also ontological intuitions, which some deflationists take to be conceptual, but which most metaphysicians take to be substantive in a way that goes beyond conceptual competence. Even if these widely held views are wrong, I think it is clear that when people deny that these states stem from conceptual competence, they are not denying that they are intuitions. Perhaps there is a delimited class of conceptual intuitions that do spring from conceptual competence, but I think that most substantive use of intuition in philosophy requires going well beyond this class.

Concerning (F2): I think the special epistemic status of intuitions, and in particular their special role in justifying other claims, is the key to the use of the notion in philosophy. In particular, it seems central to the use of intuitions in philosophy that certain intuitive claims are taken to be justified and to have the power to justify other claims, in a way that does not depend on exhibiting a justification for them. In particular, this justification does not depend on giving an argument, or on more generally on exhibiting an inferential justification. It also does not depend on a perceptual justification, or a memorial or testimonial justification, or (usually) an introspective justification. At best it depends on exhibiting an intuitive justification, along the lines of "This seems obvious".

For economy of expression, let us abuse language by saying that a justification is broadly 
inferential if it is inferential, perceptual, introspective, memorial, or testimonial. (When I omit "broadly", I mean inferential in the usual sense.) We can then say that intuitive claims have a broadly noninferential justification: justification that does not derive from any of these sources. One could argue about whether "introspective" should be included here, given the existence of introspective intuitions and given accounts of intuition on which introspection plays a role. To simplify the discussion I will exclude introspective intuitions, but a different treatment could drop "introspective" and include them. One might also worry about a purely negative characterization of intuition: is there also a positive characterization? I think there probably is a positive story about intuitive epistemic justification, but the details of such story will be somewhat controversial and not presupposed by ordinary philosophical appeals to intuition. Any reasonably neutral positive story about intuition will be thin: perhaps something to the effect that the intuitive claim seems obviously true. It is not out of the question that something like this could be fleshed out into a positive characterization, but I will stay with the negative characterization here.

The characterization of intuition in terms of broadly noninferential justification is in the spirit of Cappelen's (F2), which Cappelen himself clarifies in terms of noninferential and nonexperiential justification, but some caution is required. One subtlety (which Cappelen acknowledges): intuitions have broadly noninferential justification, so they do not need inferential justification to be justified, but they may nevertheless have inferential justification. After all, it is quite possible for a claim to be justified by more than one route. So the fact that a claim is inferentially justified does not entail that it is not an intuition. Rather, what matters is that the claim has justification that does not depend on this inferential justification.

Another subtlety: I think it is far from obvious that the intuitions that philosophers appeal to have a noninferential epistemic justification. It is quite possible that there is often some inferential justification operating under the surface, perhaps hidden from the view to the subject. It is not out of the question that a modal intuition about zombies is inferentially (but unobviously) justified by an underlying judgment about the analysis of consciousness, for example, or that a conceptual intuition about knowledge is inferentially (but unobviously) justified by an underlying judgment about the requirements for knowledge.

What matters for the use of intuitions in philosophy is their dialectical justificatory status. Here we can distinguish between epistemic justification, or what supports a subject's belief, and dialectical justification, or how a subject supports a claim to someone else. Dialectical justification is sometimes explicit, taking the form of further assertions by an agent, and is sometimes implicit, as when the speaker takes the intended justification (a perceptual justification, say) to be clear to 
other parties. Sometimes assertions are made without any dialectical justification; then a hearer may be expected to accept them based on a testimonial justification alone. What is distinctive about appeals to intuition is that intuitive claims are taken to have a dialectical justification that is broadly noninferential. That is, they are taken to be dialectically justified (for all parties) in a way that does not depend on an inferential, perceptual, memorial, introspective, or testimonial dialectical justification.

Cappelen has suggested (in discussion) that this dialectical construal of intuition is so weak that he need not oppose it. It collapses into the notion of what is taken as common ground at the start of a conversation and therefore does not need justification within the conversation. Cappelen suggests in the book that many purported intuitions are merely claims in the common ground, and he does not oppose the thesis that philosophers appeal to claims in the common ground. However, broadly noninferential dialectical justification and common ground are quite distinct. Propositions in the common ground typically have a broadly inferential dialectical justification: it is just that this justification is in the background, stemming from how the proposition entered the common ground in the first place. Often the justification will be a testimonial or perceptual justification, deriving from previous communications or from external sources. As before, these dialectical justifications need not be explicitly articulated by the parties to a conversation; they merely need to be mutually recognized. By contrast, with intuitions as I am characterizing them, there need be no broadly inferential justification that the parties recognize; there will only be a noninferential justification, perhaps associated with the obviousness of the claim in question.

Of course more needs to be said to adequately flesh out this notion of dialectical justification and the corresponding notion of intuition. For those who have doubts about the notion, I note that much of what I say in what follows applies equally to a construal of intuition in terms of epistemic justification.

I think the notion of intuition that I have articulated here is closer to the core of standard usage in informal metaphilosophical discussion than one defined in terms of (F1)-(F3). Of course, not much turns on verbal questions about "intuition". What matters is that even if Cappelen is right that philosophers do not rely on states satisfying any of (F1), (F2), or (F3), because the relevant states lack special phenomenology, have an under-the-surface inferential epistemic justification, and do not derive from conceptual competence, then the familiar philosophical self-conception will not be wholly undermined. As long as philosophers rely on claims with a broadly noninferential dialectical justification, I think a version of the widespread view that philosophers rely on intuitions can reasonably be said to be vindicated. 
I turn now to Cappelen's case against Centrality. Although Cappelen says (p. 3) that the book is an attempt to refute Centrality, and that he thinks he does so "very conclusively", it is not easy to find a direct argument against Centrality in the book. Instead, Cappelen rebuts two arguments for Centrality: an argument from 'intuition' talk, focusing on the use of 'intuition' and 'intuitively' in philosophy, and an argument from philosophical practice, appealing to evidence of features (F1)(F3) in philosophical texts. I will focus mainly on the latter, but I will make one remark about the former.

Regarding 'intuitively': Cappelen argues that there is no plausible reading of this sentence operator on which it serves to mark what philosophers take to to mark. In response, I think it is at least a hypothesis worth considering that philosophers use 'Intuitively' to mark a claim that they take to have a broadly noninferential dialectical justification. Roughly, it is way of marking that they take the claim to be justified in a way that does not require argument or other forms of broadly inferential support.

Regarding the textual evidence: here Cappelen goes through ten or so philosophical arguments that are commonly taken to involve appeal to intuition. A few of these include John Perry's "shopper" argument for the essential indexical, Tyler Burge's "arthritis" argument for antiindividualism, Judith Jarvis Thomson's "violinist" argument for the permissibility of abortion, and my "zombie" argument against materialism. In each case, Cappelen examines the original text of the argument in some detail, and finds little evidence that these authors put forward assertions satisfying (F1)-(F3).

Some preliminary worries. First, why these case studies? Of course different cases are salient to different philosophers, but I might have taken Gettier's argument from cases, Kripke's arguments against descriptivism, Jackson's knowledge argument, and Searle's Chinese room argument to be more paradigmatic appeals to intuition than any of the arguments above. Second and more important, why the original texts? Cappelen stresses a number of times that these texts often differ in surprising ways from the way their arguments are described by later philosophers and by textbooks. But insofar as there is a difference here, it is presumably the arguments as represented in later texts and textbooks that are most influential and most central to the practice of philosophy. My suspicion is that an examination of textbook presentations would not be nearly so friendly to Cappelen's case against Centrality.

Turning to the details: Cappelen's presentation of the texts is multi-faceted, and I cannot address every point he raises. But there are a few features of the text that he appeals to repeatedly. He considers various claims that are natural candidates to be intuitive claims, and observes: (1) 
Authors give arguments for these claims; (2) Instead of making these claims directly, authors make psychological or linguistic claims about subjects what subjects will say or think, and (3) Authors hedge these claims strongly and put them in highly complex forms, and (4) Authors rarely say that the claims in question have a special epistemic status, have special associated phenomenology, or derive from conceptual competence.

My view is that all four of these features are quite consistent with the view that these claims are intuitive claims in my sense above, and the presence of these features is little evidence against this view. Furthermore, I am inclined to think that all four of these features are quite consistent with the view that these claims are intuitive claims in Cappelen's sense (associated with diagnostics (F1)(F3), and provide little evidence against that view. I would go so far as to say that these features can reasonably be expected in intuition-based arguments given by reasonably sophisticated authors. So I do not think there is strong evidence against Centrality here.

Perhaps the most important textual feature that Cappelen appeals to is (1): authors give arguments for purported intuitive claims. He combines this observation with the following interpretive principle: if an author argues for $\mathrm{p}$ in context $\mathrm{C}$, that is evidence that $\mathrm{p}$ is not Rock (is not noninferentially justified) is context $\mathrm{C}$. If this principle were right, it would yield a strong case against the claims being intuitions. But I think the claim is clearly false. As I noted earlier, a claim may simultaneously have both broadly noninferential justification and inferential justification. So the presence of the latter does not entail the nonexistence of the former. It does not even tend to support the nonexistence of the former: it is to be expected that the two will often occur together in philosophical discussion.

To see this last point, note first that it is plausible that any justified claim can be given an inferential justification: one can argue for anything. And note second that if a justification is available for a claim, it is to be expected that philosophers will appeal to it. This applies especially to the inferential justfication available for intuitive claims. One is in a better dialectical position if one can supplement a noninferential justification with an inferential justification. The former on its own can seem flat-footed and dialectically thin, and open to simple denials. The latter at least strengthens the dialectical support and forces an opponent to work harder to reject the claim. So there are good sociological reasons to take Cappelen's interpretive principle to be false.

A clear illustration is provided by Gettier's argument that knowledge is not justified true belief. As Cappelen notes, Gettier first asserts a claim $C$ about a case, holding that the subject in question does not know the relevant proposition. He immediately follows this assertion by an argument for $C$ from the principle $P$ that beliefs inferred from false beliefs are not knowledge. This argument 
clearly puts him in a more robust dialectical position, but at the same time it is entirely compatible with the natural view that the claim that $C$ has broadly noninferential dialectical justification: even without the inferential justification from $P, C$ would have been dialectically justified. This dialectical justification is reflected by the many textbooks and later texts that present a Gettierstyle argument from $C$ without giving Gettier's argument from $P$ to $C$. I think in fact it is plausible that both $C$ and $P$ have broadly noninferential support, and that both of them also have inferential support deriving from each other (one can argue from $C$ to $P$ or from $P$ to $C$ ). This is a common situation in philosophy, and it is unsurprising that Gettier appeals to both sorts of support for $C$ to make his case as robust as possible.

Something very similar applies to my own presentation of the conceivability argument against materialism. In that presentation, I first appeal to the conceivability of zombies, saying I take this to be intuitively obvious (and therefore noninferentially dialectically justified), but I go on to give a number of arguments for this claim from underlying principles (for example, the nonanalyzability of consciousness in functional terms). These arguments strengthen the case for the conceivability premise, but they certainly do not exhaust the case. Furthermore, while the principles are themselves somewhat intuitive, they can also themselves be supported by an appeal to the conceivability of zombies. This sort of mutual support among cases and principles each of which itself has some noninferential dialectical support is widespread in philosophy. Something like it is enshrined in the method of reflective equilibrium. The common use of structures like this gives good reason to reject Cappelen's interpretive principle and the corresponding case against Centrality.

Regarding (2), Cappelen often notes that in place of alleged intuitions p, authors assert psychological/linguistic claims such as "People will say p", "Everyone finds it plausible that p", "You would find the claim that not-p outrageous". He then notes that these claims are plausibly empirically supported and are not plausibly intuitions. In response, I think it is plain that this is a natural way of talking when one takes $p$ to have prima facie intuitive support. We naturally move between the first-order and psychological modes.

Something similar goes for (3), the uses of hedges, qualifications, and complexity. These are only to expected. After all, in most cases the relevant noninferential justification is prima facie justification, and there are many complex surrounding issues that have the potential to defeat the justification. To simply assert $p$ without qualification would be flat-footed, and few of the philosophers under discussion are flat-footed as this.

Cappelen appeals to the point regarding complexity in his discussion of my conceivability 
argument against materalism. He notes that in later work, I clarify the claim that zombies are conceivable as the following claim: " $P \& \neg Q$ is ideally primarily (negatively) positively conceivable", and that the components such as "ideally" here themselves receive a complex analysis. He notes that this complex claim is not plausibly an intuition and is rather something that requires argument. There is much to say here. For a start, I think the dialectical structure appealed to in the later text is quite different from that of the earlier text (intuitions play a much less focal role), so the former does not provide strong evidence about the latter. But even where the notions used in the later text are concerned, I note that (i) ideal negative conceivability claims can be understood as an a priori consistency claim, and these are claims one can plausibly have broadly noninferential justification for, and (ii) the ideal positive and negative conceivability claims can be supported by the prima facie positive conceivability of zombies, and these prima facie conceivability claims plausibly have broadly noninferential dialectical support. So I do not think that Cappelen's observations do much to undermine the suggestion that the appeal to the conceivability of zombies (especially in The Conscious Mind) has broadly noninferential dialectical support and is presented as such.

As for (4), the observation that authors rarely say that the claims in question have a special epistemic status, have special associated phenomenology, or derive from conceptual competence: my earlier discussion suggests that phenomenology and conceptual competence are not really to the point here, and that what matters is that claims have a special dialectical status. We should not expect this status to always be explicitly signalled. I think that it is sometimes signalled, though, and that the sort of locution discussed under (2) above is one way to signal it. Another is the use of "intuitively" and explicit appeals to intuition. Cappelen notes that I make such appeals myself, only to dismiss them with the observation that authors' metaphilosophical views are not infallible guides to their first-order arguments. Perhaps not, but it is hard to know what could serve as better textual evidence that an author is appealing to intuition than the remark that they are appealing to intuition.

To step back: I do not take myself to have provided conclusive positive textual evidence that philosophers rely on intuition in a widespread way. I think that there is some reasonably strong evidence provided by direct appeals to intuition, and that examination of textbooks and later texts may provide better evidence in many cases than the original texts. But even if Cappelen were right that the textual argument for Centrality does not succeed, it would not follow that he has given a strong textual argument against Centrality. That would require a principle along the lines of "absence of (textual) evidence is (textual) evidence of absence". I think the discussion above gives good reason to reject such a principle, as the textual features he notes are largely to be expected 
even if Centrality is true. So I think that Cappelen has not made a strong case against Centrality.

Perhaps Cappelen is really trying only to undercut support for Centrality, and not to refute Centrality. But to do even this, he would need to address all important sources of support, and it is not clear that he has done that. In my view, the best reasons to accept Centrality are not grounded wholly in the examination of texts. Instead, they are grounded partly in non-text-based reflection on the structure of arguments. In many cases, we can reflect on dialectically and epistemologically effective arguments that are available for a given thesis (whether or not anyone makes these arguments), and come to the conclusion that some of these arguments involving premises with broadly noninferential support. I think that there is good philosophical reason to think that relevant judgments about the Gettier or Burge or Jackson case have broadly noninferential justification, for example. No textual analysis is required to make this point, and as far as I can tell Cappelen provides no arguments against it. But when the point is combined with the plausible claim that philosophers will use effective arguments when they are available, it provides good reason to accept a role for intuitions in philosophy. And when these non-textual points are combined with evidence about specific texts, they provide good reason to think that the texts are invoking these arguments.

More generally, reflection on the structure of justification yields a case that one has to appeal to intuitions (as I construe them) to get anywhere in philosophy. After all, all arguments have to start somewhere. Some premises will have background support, but even once one unpacks this support, there will plausibly be unargued premises without inferential support. In some cases this noninferential support will derive from perceptual or introspective support, but it is arguable that inference from perception and introspection is not strong enough to get one to strong philosophical conclusions in many cases. So philosophical argumentation for these strong conclusions will rely at some level on broadly noninferential (that is, intuitive) justification.

Of course there are various possible responses to this flatfooted attempt at a transcendental argument for intuition (for a more sophisticated attempt, see Bealer 1992). Coherentists may hold that inferential justification does not rely on noninferential support, and some naturalists will hold that abductive inference from perception can get us to strong philosophical conclusions. Even if one accepts these views, though, it is arguable that even our acceptance of basic inference rules requires intuitive support at some level (though the issues here are notoriously complex). In any case, the argument at least makes a prima facie case to be answered.

Where does all this leave Cappelen's thesis of philosophical exceptionalism (which he takes to be built in to Centrality): that philosophers rely on intuition to an extent that other fields do not? 
One might worry that the argument above generalizes to other fields, and that my watered-down notion of intuition will not support this exceptionalism. Indeed, I am inclined to think that all domains of human inquiry rely on intuitions to some extent, so that philosophy is not strongly exceptional here. Still, I think that philosophy differs in at least some matters of degree: the use of intuitions in philosophy is more extensive, more focal, and more subject to disagreement than in many other fields, such as mathematics and the sciences.

First, extensiveness. To do mathematics (or at least the formal version of mathematics presented in journals), one arguably needs intuition only to justify a few basic axioms and inference rules. Inferential justification can do the rest. To do much of science, one arguably only needs to augment perception with mathematics along with some principles of hypothesis testing that are arguably grounded in intuition. Here the role of intuition at least seems delimited. But for philosophical purposes, no similarly delimited set of intuitions will suffice. It is arguable that we need a large and open-ended class of intuitions for philosophical purposes.

Second, focality. In science and mathematics, the role of intuition is largely in the background. In mathematics, the axioms and inference rules are rarely focal. In science, principles of hypothesis testing, prior probabilities, and the like are typically left in the background, with observations and theories being focal. Indeed, scientists often object to Bayesian methods of hypothesis testing because they require intuitions about prior probability to be focal rather than backgrounded. By contrast, in philosophy, intuitive judgments are focal, being explicitly articulated and a major source of attention.

Third, disagreement. In mathematics, there is little disagreement over the relevant intuitions. In science, there may be some disagreement over priors and principles of hypothesis testing, but this disagreement tends to wash away in the long run. In linguistics (where reliance on intuition is extensive and focal), intuitions of grammaticality are usually widely shared. But in philosophy, there is often extensive disagreement about the relevant intuitions that does not get washed away in the long run.

What, finally, of the epistemological and methodological worries that intuition often gives rise to? Cappelen uses his case against Centrality to make the case that these worries are often misguided. Does my minimal conception of intuition support these worries or avoid them? I am inclined to think that the worries still arise on this conception.

First, there is clearly an epistemological challenge about how any judgment could have broadly noninferential support. The kind of epistemic justification associated with intuitive judgments remains something of a mystery and we do not have widely accepted models of it. This worry 
applies to uses of intuition in science and mathematics as well as in philosophy, but the extensiveness, focality, and disagreement involving intuitions in philosophy makes the epistemological challenge especially pressing here.

Second, there is a methodological challenge about why we should accept a claim whose dialectical justification is broadly noninferential when there is disagreement over the claim. The disagreement seems to suggest that this dialectical justification is not universally recognized, which tends to reduce its force. When there is disagreement about a claim with broadly inferential support, one can exhibit that support in response; and where there is little disagreement about broadly noninferential intuitions, as in the case of mathematical axioms and linguistic judgments, the dialectical justification is not challenged in this way. But in philosophy, where disagreement over such intuitions is widespread (both among philosophical interlocutors, as is familiar from everyday philosophical practice, and across different societal groups, as is brought out by work from experimental philosophy), a distinctive methodological challenge arises.

All in all: I conclude that there is a minimal construal of intuitions as judgments with broadly noninferential support such that (i) this construal reflects the way the notion is used in philosophical practice, (ii) it is plausible that philosophy relies significantly on intuitions in this sense, and (iii) this reliance raises significant epistemological and methodological worries. If space and time

permitted, it would be nice to address those epistemological and methodological worries, but I must leave that as a task for another occasion.

\section{References}

Bealer, G. 1992. The incoherence of empiricism. Proceedings of the Aristotelian Society, Supplementary Volume 66:99-138.

Cappelen, H. 2012. Philosophy without Intuitions. Oxford University Press. 